
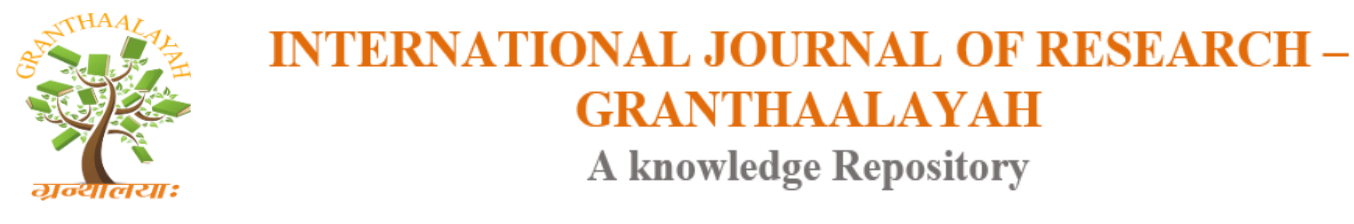

Social

\title{
DEMOGRAPHIC CHARACTERISTICS AND INTERNAL MEDICINE AS A CAREER CHOICE OF FINAL YEAR MEDICAL STUDENTS
}

\author{
Shivani Dhodi ${ }^{1}$, Prof. Indu Bansal ${ }^{2}$ \\ ${ }^{1}$ Research Scholar, Banasthali Vidhya Pith, India \\ ${ }^{2}$ Dean, Faculty of Home Science, Banasthali Vidhya Pith, India
}

\begin{abstract}
Introduction: Medical education requires a long duration of education and training. Medical stream is a diverse field; an assortment of clinical specialties of number of areas; clinical, psychological, surgical, field work, public health to name a few, with varied clinical environment, duties, and contact with patients.

Methodology: Study was conducted in ten Medical colleges from three northern states of India (Uttar Pradesh, Punjab and Chandigarh). 677 final year medical students were included in the study. The study was designed as a cross-sectional self- administered questionnaire-based survey. Data were analyzed based on Frequencies, percentage, weighted scores and Chi square test. The findings were tabulated and represented with the help of suitable diagrammatic and graphical presentation.

Results: revealed that around two-third were males (67.50\%), majority were under 25 years, Hindus, from urban areas, joint families and 6.79\% were married. Majority belonged to HIG. Statistically significant association of some demographic Characteristics (area of residence, gender, marital status and type of family) in selection of Internal medicine as specialty choice, whereas the association was not significant for age, religion and income group.
\end{abstract}

Keywords: Demographic; Internal Medicine; Medical Students.

Cite This Article: Shivani Dhodi, and Indu Bansal. (2018). "DEMOGRAPHIC CHARACTERISTICS AND INTERNAL MEDICINE AS A CAREER CHOICE OF FINAL YEAR MEDICAL STUDENTS." International Journal of Research - Granthaalayah, 6(9), 206211. https://doi.org/10.5281/zenodo.1442415.

\section{Introduction}

Medical education requires a long duration of education and training. Medical stream is a diverse field; an assortment of clinical specialties of number of areas; clinical, psychological, surgical, field work, public health to name a few, with varied clinical environment, duties, and contact with patients. It takes five to seven years of learning to earn MBBS degree, Medicine undergraduate students had to study a wide range of basic science subjects, medical subjects and intensive training with exposure to varied clinical environment, duties, and contact with patients. This helps the 
individual to decide upon which speciality to pursue after completion of their medical graduation, while some of students take a decision to go for general practice. Medical careers begin undifferentiated ultimately into fully-differentiated specialists whose practice is almost entirely confined to one specialized branch of medicine. Today, one has not only to make due career planning but also exhaustive career research before making a career choice so as to adjust with the evolving socio-economic conditions (Wattles, 2009).

Medical stream is a diverse field; an assortment of clinical specialties of number of areas; clinical, psychological, surgical, field work, public health to name a few, with varied clinical environment, duties, and contact with patients. In medicine field, the career interests of students might have a significant routing outcome on the number of existing medical personnel and their allocation. As far as students' efforts are concerned, medical education system in Indian scenario is demanding, delivering too much content in a short span of time with more traditional approach of teaching; more class room teacher centered interaction, based on examination and laboratory oriented. Kumar and Dhaliwal (2011) also reported that the most preferred career choices were medicine and surgery, followed by orthopaedics, and least choosen was community medicine.

\section{Statement of Problem}

The challenge for medical educationists is to understand how these choices are made and design curricula to influence these choices. Therefore, it is very important to find the impact of demographic characteristics on career choice of medical students. Therefore keeping all points in mind the problem has been stated as - "Demographic characteristics and Internal Medicine as a career choice of final year medical students" With the following objective: To study specialty preference of medical students and to find out influence of demographic characteristics on specific specialty choices of medical students.

\section{Methodology}

Study was conducted in ten Medical colleges from three northern states of India (Uttar Pradesh, Punjab and Chandigarh). All the medical final year students were included in the study. Out of 910 medical final year students, 823 responded to the questionnaires (response rate $90.43 \%$ ). Of these received back, 32 students had not completed all the sections of the questionnaires and were excluded from the study. Since study was focused on students interested in further studies; 114 interested in general practice were not included in the analysis. Hence sample for the study consisted of 677 final year medical students. The study was designed as a cross-sectional selfadministered questionnaire-based survey. After a detailed review of existing literature a semi structured questionnaire was developed in English including close as well as open ended questions. Preliminary draft questionnaire was given to a group of 10 medical students to obtain their feedback. Final questionnaire was then subjected to a validation by giving it to 10 medical professionals for check of item appropriateness and comprehensiveness. The questionnaire began with instructions to the participants followed by demographic data, questions regarding the choice of specialties and subspecialties. Data were analyzed based on Frequencies, percentage, weighted scores and Chi square test. The findings were tabulated and represented with the help of suitable diagrammatic and graphical presentation. 


\section{Results}

\subsection{Demographic Characteristics of Respondents}

Response Rate - As mentioned in earlier chapter out of 910 questionnaires distributed, 823 questionnaires (with 32 uncompleted questionnaires) were received back (response rate 90.43\%). Out of completed questionnaires, 114 showed their interest in general practice. Since study was focused on students interested in further studies, therefore 677 responses were analyzed. A number of researchers feel that demographic measures are important to include in research (Entwisle \& Astone, 1994; Hauser, 1994). Social constructs such as religion, family type, gender and marital status, may influence students overall persona. Most children are not independent specially in India, where parents are the basis for the financial capital; therefore where their finances come from will help explain their SES (Entwisle \& Astone, 1994).

Table 1: Demographic profile of medical students $(\mathrm{N}=677)$

\begin{tabular}{|l|l|l|}
\hline Demographic Characteristics & Variables & Frequency/ Percentage \\
\hline \multirow{4}{*}{ Age } & Male & $457(67.5)$ \\
\cline { 2 - 3 } & Female & $220(32.5)$ \\
\hline \multirow{2}{*}{ Marital status } & Below 25 & $668(98.67)$ \\
\cline { 2 - 3 } & 25 and above & $9(1.33)$ \\
\hline \multirow{5}{*}{ Religion } & Married & $46(6.79)$ \\
\cline { 2 - 3 } & Unmarried & $631(93.21)$ \\
\hline \multirow{5}{*}{ Residence Area } & Hindu & $586(86.56)$ \\
\cline { 2 - 3 } & Muslim & $66(9.75)$ \\
\cline { 2 - 3 } Type of family & Sikh & $10(1.48)$ \\
\cline { 2 - 3 } & Christian & $15(2.22)$ \\
\hline Income group & Urban & $490(72.38)$ \\
\cline { 2 - 3 } & Rural & $187(27.62)$ \\
\hline & Nuclear & $260(38.4)$ \\
\cline { 2 - 3 } & Joint & $417(61.6)$ \\
\hline & LIG & $118(17.43)$ \\
\cline { 2 - 3 } & MIG & $178(26.29)$ \\
\cline { 2 - 3 } & HIG & $381(56.28)$ \\
\hline
\end{tabular}

\section{Empirical Analysis}

As evident from the above table, around two-third were males (67.50\%) against 220 females (32.5); it evinces that medical profession is still more male dominated. Most of the medical students complete their graduation by the age of 25 years (as $98.67 \%$ were below 25 year of age and $6.79 \%$ were married.

When analyzed for religion wise distribution majority were Hindus (86.55\%) followed by Muslims $(9.74 \%)$ and small percentage belonged to either Christian $(2.21 \%)$ or Sikh $(1.47 \%)$ religion. Majority belonged to urban areas whereas slightly more than one fourth (27.62\%) were from rural area. 
It is also worthwhile to note here that a majority of respondents were from joint families as only $38.40 \%$ were from nuclear families.

Income is also one of factors influencing medical career as was evident from the fact that majority belonged to HIG followed by MIG (26.29\%) and only $17.42 \%$ were in LIG category.

\section{Internal Medicine; Sub- Speciality Preferences Among Medical Students}

15 sub specialties were included under Internal medicine. Internal medicine aspirants $(n=159)$ were asked to give five sub speciality choices in order of preference from 1 (most preferred) to 5 (fifth preference). Sub speciality wise preferences have been reported in the table below:

Table 2: Internal medicine: sub specialty preference of medical students

\begin{tabular}{|c|c|c|c|c|c|c|c|}
\hline \multirow{2}{*}{$\begin{array}{l}\text { Internal medicine } \\
\text { sub- speciality }\end{array}$} & \multicolumn{5}{|c|}{ Preferences } & \multirow[t]{2}{*}{ Total scores } & \multirow[t]{2}{*}{ Rank } \\
\hline & I & II & III & IV & $\mathrm{V}$ & & \\
\hline Allergy / Immunology & 2 & 12 & 15 & 0 & 0 & 103 & 14 \\
\hline Andrology & 18 & 13 & 9 & 7 & 6 & 189 & 3 \\
\hline Angiology (Vascular Medicine) & 8 & 14 & 6 & 8 & 15 & 145 & 9 \\
\hline Cardiology & 23 & 16 & 2 & 13 & 8 & 219 & 2 \\
\hline Endocrinology & 6 & 19 & 7 & 9 & 17 & 162 & 7 \\
\hline Gastroenterology & 1 & 17 & 3 & 19 & 11 & 131 & 11 \\
\hline Geriatrics & 4 & 10 & 0 & 8 & 6 & 82 & 15 \\
\hline Gynaecology & 35 & 8 & 8 & 16 & 8 & 271 & 1 \\
\hline Hematology & 18 & 7 & 12 & 8 & 13 & 183 & 5 \\
\hline Hepatology & 14 & 8 & 12 & 17 & 13 & 185 & 4 \\
\hline Infectious disease & 11 & 8 & 16 & 14 & 17 & 180 & 6 \\
\hline Nephrology & 2 & 3 & 24 & 13 & 12 & 132 & 10 \\
\hline Oncology & 3 & 9 & 27 & 7 & 12 & 158 & 8 \\
\hline Pulmonology & 8 & 8 & 6 & 14 & 13 & 131 & 12 \\
\hline Rheumatology & 6 & 7 & 12 & 6 & 8 & 114 & 13 \\
\hline
\end{tabular}

\section{Empirical Analysis}

Data revealed that students interested in internal medicine perceived gynecology as their first preference followed by Cardiology, Andrology and Hepatology and Hematology. Second preference reported were most for Endocrinology, then Cardiology, followed by Gastroenterology and Andrology.

When compared for overall Internal medicine sub speciality preferences, Gynecology was still among the most preferred sub speciality of internal medicine, followed by Cardiology. Almost equal weightage was for Andrology, Hepetology, Hematology and Infectious diseases. Geriatrics was least preferred sub speciality. Allergy/ immunology and Rheumatology were also not a preferred choice of Internal medicine aspirants. 
Table 3: Association of demographic characteristics with internal medicine as career choice of medical students

\section{*Significant}

\begin{tabular}{|c|c|c|c|}
\hline Attributes & Variable & df & Chi Square \\
\hline Gender & Male & \multirow[t]{2}{*}{3} & \multirow[t]{2}{*}{$13.04 *$} \\
\hline & Female & & \\
\hline \multirow[t]{2}{*}{ Age } & Below 25 & \multirow[t]{2}{*}{3} & \multirow[t]{2}{*}{1.98} \\
\hline & 25 and above & & \\
\hline \multirow[t]{2}{*}{ Marital status } & Married & \multirow[t]{2}{*}{3} & \multirow[t]{2}{*}{$13.04 *$} \\
\hline & Unmarried & & \\
\hline \multirow[t]{4}{*}{ Religion } & Hindu & \multirow[t]{4}{*}{9} & \multirow[t]{4}{*}{9.37} \\
\hline & Muslim & & \\
\hline & Sikh & & \\
\hline & Christian & & \\
\hline \multirow[t]{2}{*}{ Residence area } & Urban & \multirow[t]{2}{*}{3} & \multirow[t]{2}{*}{$9.29 *$} \\
\hline & Rural & & \\
\hline \multirow[t]{2}{*}{ Type of family } & Nuclear & \multirow[t]{2}{*}{3} & \multirow[t]{2}{*}{$23.34 *$} \\
\hline & Joint & & \\
\hline \multirow[t]{3}{*}{ Income group } & LIG & \multirow[t]{3}{*}{6} & \multirow[t]{3}{*}{6.74} \\
\hline & $\mathrm{MIG}$ & & \\
\hline & $\mathrm{HIG}$ & & \\
\hline
\end{tabular}

\section{Empirical Analysis}

Perusal of the table above indicated statistically significant association of some demographic attributes (area of residence, gender, marital status and type of family) in selection of Internal medicine as speciality choice, whereas the association was not significant for age, religion and income group.

As evident from the above table, more female respondents indicated first preference for internal medicine than their male counterparts. This study is in support with other study. (Scott et al. 2008) It is also worthwhile to report here that although the Internal Medicine was the first choice of more or less equal percentage of married and unmarried respondents but given second preference by more married students (45.65\% as against $37.40 \%$ ) than their unmarried counter parts and same is true for Urban respondents vis- a -vis Rural respondents.

Family wise comparison indicated that Internal medicine was first or second choice of more joint family respondents.

\section{Suggestions for Further Research}

- Research should thus focus on both applicant and institutional characteristics. So to plan undergraduate and postgraduate medical training in totality.

- Statewise medicasl colleges can also be compared for curriculum, factors of influence and their perceived suggestions for improvement in health care system.

- Cohort study can also be undertaken as it can provide with varied results. 
- Comparative study can be planned for entrants and graduating medical students. Study can also be done on health personnels from other fields of medicine.

\section{References}

[1] Kumar, R. and Dhaliwal, U. (2011) Career choices of undergraduate medical students The National Medical Journal of India Vol. 24, No. 3, 2011

[2] Entwisle, D.R. and Astone, N.M. (1994). Some practical guidelines for measuring youth's race/ethnicity and socioeconomic status. Child Development, 65(6), 1521-1540.

[3] Hauser, R.M. (1994). Measuring socioeconomic status in studies of child development. Child Development, 65(6), 1541-1545.

[4] Scott, I. M., Matejcek, A. N., Gowans, M.C., Nut, Diet, M., Wright, B.J. and Brennels, F. R. (2008) Choosing a career in surgery: factors that influence Canadian medical student's interest in pursuing a medical career. Canadian Journal of surgery, 51:371-377.

\footnotetext{
*Corresponding author.

E-mail address: shivani.0.dhodi@gmail.com
} 